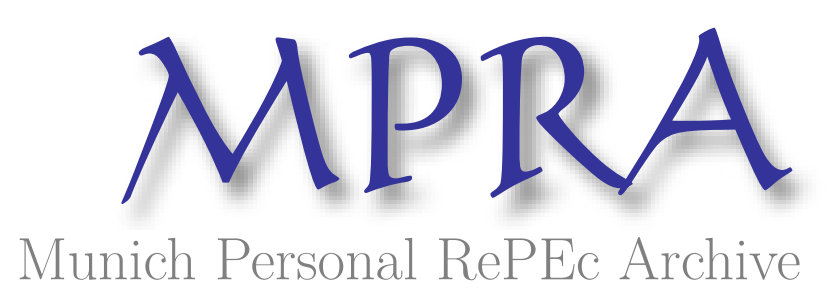

\title{
Nation States vs. United Empire: Effects of Political Competition on Economic Growth
}

\author{
Chu, Angus C. \\ Institute of Economics, Academia Sinica
}

18 April 2008

Online at https://mpra.ub.uni-muenchen.de/8320/

MPRA Paper No. 8320, posted 18 Apr 2008 14:41 UTC 


\title{
Nation States vs. United Empire: Effects of Political Competition on Economic Growth
}

\author{
Angus C. Chu ${ }^{*}$ \\ Academia Sinica
}

April 2008

\begin{abstract}
Is the European nation-state system more favorable to economic growth than the united-empire system in ancient China? This paper develops an endogenous-growth model to analyze the conditions under which economic growth is higher under political fragmentation than political unification. Under political unification, the economy is vulnerable to excessive Leviathan taxation and the costs of unifying heterogeneous populations. Under political fragmentation, the competing rulers are constrained in taxation but spend excessively on military defense. If and only if the heterogeneity costs are sufficiently high relative to the mobility cost of citizens or equilibrium defense spending, then political fragmentation would be more favorable to growth than political unification. When the political regime is endogenously chosen by rulers, they do not always choose the growth-maximizing regime. In particular, there exists a range of values for the heterogeneity costs, in which political fragmentation is more favorable to growth but the rulers prefer political unification.
\end{abstract}

Keywords: endogenous growth, Leviathan taxation, interstate competition, endogenous political regime JEL classification: D72, H20, H56, O41, O43

\footnotetext{
* Institute of Economics, Academia Sinica, Taipei, Taiwan. Email address: angusccc@econ.sinica.edu.tw. I would like to thank Dmitriy Stolyarov for his insightful comments and very helpful suggestions. All errors are, of course, mine.
} 


\section{Introduction}

Is the European nation-state system more favorable to economic growth than the united-empire system in ancient China? A number of economic historians, such as North (1981) and Jones (1981), argue that the unique European nation-state system contributed to its economic takeoff in the late $18^{\text {th }}$ and early $19^{\text {th }}$ century while the united-empire system in China was responsible for its economic stagnation during that period. ${ }^{1}$ For example, North (1981) suggests that the interstate competition arising from political fragmentation induces the competing rulers to recognize private property rights in order to prevent labor and human-capital outflows, and the resulting economic system with secured property rights creates the proper environment for capital accumulation and hence sustained growth. However, Bernolz and Vaubel (2004) note that political fragmentation did not always lead to these predicted effects.

"Political fragmentation is not a sufficient condition for political competition, innovation and growth but it is a necessary condition for interstate competition and for a high probability of sustained innovation and growth... Political fragmentation will not lead to interstate competition unless there is considerable mobility among jurisdictions... Political fragmentation will not favour innovation and growth if it leads to prolonged and highly destructive wars rather than limited warfare or peaceful competition for manpower and capital."

Bernolz and Vaubel (2004, p. 14)

So, under what conditions would political fragmentation be more favorable to economic growth than political unification? In addition, given that political regimes are endogenous, why did so many ancient civilizations adopt the united-empire system if the nation-state system is indeed more favorable to economic growth?

\footnotetext{
${ }^{1}$ See, for example, Bernholz et al (1998) and Bernholz and Vaubel (2004) for a comprehensive survey.
} 
To answer these questions, this paper develops an endogenous-growth model, in which economic growth is a function of the investment rate chosen by citizens and the income-tax rate chosen by rulers, ${ }^{2}$ and uses the model to analyze the conditions under which the growth rate is higher under political fragmentation than political unification. On one hand, political fragmentation can be advantageous to growth because the competition between rulers limits their ability in taxing the citizens. The degree of this limitation is governed by the mobility cost of the citizens, and this mobility cost is meant to capture North's (1981) idea that the monopoly power of a ruler is a function of the closeness of available substitutes and the opportunity cost of exit for the citizens. On the other hand, political fragmentation can be damaging to growth if the competing rulers allocate an excessive amount of productive resources to military defense. In the case of political unification, the level of output and economic growth are reduced by the heterogeneity costs arising from unifying heterogeneous populations into a single country. ${ }^{3}$

In summary, under political unification, the economy is vulnerable to excessive Leviathan taxation and the heterogeneity costs. Under political fragmentation, the competing rulers are constrained in taxation but spend excessively on military defense. The theoretical analysis suggests that whether political fragmentation or political unification is more favorable to growth depends on the relative magnitude of the heterogeneity costs, the mobility cost of citizens and the equilibrium amount of defense spending. If and only if the heterogeneity costs are sufficiently high relative to the mobility cost or defense spending, then political fragmentation would be more favorable to growth than political unification. Furthermore, as the ruler becomes more impatient, the parameter space in which political fragmentation is more favorable to growth increases. Intuitively, as the ruler becomes more impatient, he/she would prefer to levy a higher tax rate; therefore, it becomes more likely for the competition between rulers that limits taxation to provide a more favorable effect on growth.

\footnotetext{
2 This formulation of using taxation as a measure of property rights is motivated by Drazen's (2000, p. 459) obersvation that “... property rights can be considered in the narrow sense as applying to taxation of property: even in the absence of the threat of outright expropriation, societies can nonetheless legally expropriate the fruits of accumulation via taxation."

${ }^{3}$ The inclusion of these heterogeneity costs is meant to capture some of the insights from the literature on country formation. See, for example, Alesina and Spolare (2003) for a comprehensive discussion on this literature.
} 
When the political regime is endogenously chosen by the rulers, they do not always choose the growth-maximizing regime. In particular, there exists a range of values for the heterogeneity costs, in which political fragmentation is more favorable to growth but the rulers prefer political unification. On one hand, when the heterogeneity costs are sufficiently high, economic growth is higher under political fragmentation than political unification. On the other hand, the rulers suffer from a reduction in the level of tax revenue under political fragmentation because the mobility of citizens sets an upper limit on the tax rate. When the heterogeneity costs are not excessively high, this negative level effect dominates the positive growth effect and the emperors enjoy a higher level of utility under political unification. In this case, although political fragmentation favors economic growth, political unification arises as the equilibrium outcome. As for the citizens, they always prefer the political regime that is more favorable to growth; therefore, there are situations in which the citizens and the rulers prefer different political regimes.

\section{Related Literatures}

This paper relates to a number of literatures: (a) institutional economics and economic history; (b) endogenous-growth theory; (c) the political economy of Leviathan taxation; (d) the literature on country formation; and (e) the political economy of growth. This paper formalizes the insights from a number of economic historians on the effects of political fragmentation on growth using a version of the so-called AK endogenous-growth model. ${ }^{4}$ In particular, it embeds a framework of Leviathan taxation into the growth model to analyze the conditions under which the interstate competition arising from political fragmentation would constrain the tax rate chosen by Leviathans and enhance growth. ${ }^{5}$ Furthermore, it borrows some of the insights from the literature on country formation to analyze the different growth effects of political fragmentation and political unification. Alesina and Spolare (2005) analyze how the heterogeneity costs and the cost of international conflict affect the size and the number of nations. ${ }^{6}$ In

\footnotetext{
${ }_{5}^{4}$ See, for example, Rebelo (1991) for a discussion on the different versions of the AK model.

${ }^{5}$ See, for example, Brennan and Buchanan (1977), Grossman and Noh (1994) and Grossman (2002) for studies in the political economy of Leviathan taxation.

${ }^{6}$ See, also, Alesina and Spolare (2003, chapters 7 and 8).
} 
contrast, the current paper firstly analyzes how these factors affect economic growth for a given size and number of nations. Then, it considers whether the political regime that is more favorable to growth would emerge as the equilibrium outcome. ${ }^{7}$

The rest of the paper is organized as follows. The next section presents the model and results. The final section concludes with a discussion on the implications of the model.

\section{The Model}

There is a continuum of identical households residing in each of the two symmetric regions. In the case of political unification, the level of output decreases by a fraction $h$ that captures the heterogeneity costs in unifying two heterogeneous populations. ${ }^{8}$ The unified country is ruled by an emperor, who chooses the tax rate and consumes the tax revenue to maximize his/her lifetime utility. Taking the tax rate as given, the households make the intertemporal consumption-saving decision to maximize their lifetime utility. Because of constant returns to scale with respect to the cumulative input factor in the production function, the output growth rate is determined by the households' investment rate and the tax rate.

In the case of political fragmentation, each of the two countries is ruled by an emperor, who makes an additional decision on the amount of defense spending for the purpose of capturing a larger amount of land, which is a productive factor input. The households also have to make an additional decision on the residential location. For the households from one region to move to the other region, they face a mobility cost that reduces their output by a fraction $m$. The magnitude of this mobility cost determines the extent of tax competition between the two emperors. For a low value of $m$, the emperors have to set a lower tax rate than desired in order to prevent the outflows of labor and human capital.

\footnotetext{
${ }^{7}$ See, for example, Drazen (2000, chapter 11), Persson and Tabellini (2000, chapter 14) and Acemoglu (2008, chapters 22 and 23) for excellent surveys in the political economy of growth.

${ }^{8}$ Potential sources of these costs include conflicting preferences over public policies, coordination costs, monitoring costs, or even the expected losses associated with civil wars. See, for example, Alesina and Spolare (2003, 2005).
} 


\section{Households}

There is a continuum of representative households on the unit interval in region $j \in\{a, b\}$, and their lifetime utility is

$$
U(j)=\int_{0}^{\infty} e^{-\rho t} \ln C_{t}(j) d t,
$$

where $C_{t}(j)$ denotes the level of consumption for a household in region $j$ at time $t$, and $\rho \in(0,1)$ is the household's subjective discount rate. To simplify notation, I will suppress the regional index $j$. In each period, the households use their human capital $H_{t}$ to produce goods, and they decide how much to consume and invest in human capital by maximizing utility subject to a sequence of budget constraints given by

$$
\dot{H}_{t}=\left(1-\tau_{t}\right) Y_{t}-C_{t}-H_{t} \delta
$$

where $\tau_{t}$ is the income-tax rate and $\delta \in[0,1)$ is the depreciation rate of human capital. $Y_{t}$ is the amount of goods produced. Following the literature on AK endogenous growth, the production is assumed to have constant returns to scale with respect to the cumulative input factor such that $Y_{t}=A_{t} H_{t}$. To incorporate some interesting elements from the country-formation literature into the model, the level of productivity denoted by $A_{t}$ is assumed to be a function of land $L_{t}$ and the heterogeneity costs $h \in(0,1)$ given by

$$
A_{t}=\left(1-\gamma_{t} h\right) L_{t}
$$

$\gamma_{t}$ is an $0-1$ indicator that equals 1 in the case of political unification and equals 0 in the case of political fragmentation.

\section{Emperor(s)}

In the case of political unification, there is an emperor governing the unified country. In the case of political fragmentation, there are two uncooperative emperors governing the two independent countries. An emperor's utility is 


$$
\tilde{U}=\int_{0}^{\infty} e^{-\beta t} \ln T_{t} d t,
$$

where $T_{t}$ is the tax revenue net of defense spending, and $\beta \in(0,1)$ is the emperor's discount rate.

\section{Political Unification}

In the case of political unification, the emperor allocates the amount of land equally among the two populations. The amount of goods produced in each region is $Y_{t}=(1-h) H_{t}$, where the total amount of land is normalized to two. Because the emperor incurs zero defense spending, the amount of tax revenue consumed by him/herself is $T_{t}=\tau_{t} Y_{t}$ from each region. Denote $c_{t}$ as the fraction of after-tax income consumed by the households (i.e. $\left.C_{t}=c_{t}\left(1-\tau_{t}\right) Y_{t}\right)$ and $1-c_{t}$ as the investment rate on human-capital. Taking $\tau_{t}$ as given, the households choose $c_{t}$ to maximize (1) subject to (2). Then, taking the solution $c_{t}\left(\tau_{t}\right)$ as given, the emperor chooses $\tau_{t}$ to maximize (4) subject to (2).

Lemma 1: Under political unification, the balanced-growth equilibrium outcomes are

$$
\begin{gathered}
c^{u}=\frac{\rho}{\left(1-\tau^{u}\right)(1-h)}, \\
\tau^{u}=\beta /(1-h), \\
g^{u}=\left(1-\tau^{u}\right)(1-h)-(\rho+\delta)=1-(h+\beta+\rho+\delta) .
\end{gathered}
$$

Proof: See Appendix A. $\square$

$g^{u}$ is the balanced-growth rate of per capita output. Firstly, $g^{u}$ is decreasing in $\rho$ because an increase in $\rho$ reduces the investment rate in human capital. Secondly, $g^{u}$ is decreasing in $\beta$ because an increase in $\beta$ leads to a higher tax rate that reduces the rate of return on human capital. Finally, $g^{u}$ is decreasing in 
$h$ and $\delta$ because they reduce the net rate of return on human capital. To ensure that the balanced-growth equilibrium is well-behaved, the following parameter conditions are assumed.

$$
\begin{gathered}
g^{u}<\beta \Leftrightarrow 1-(h+\rho+\delta)<2 \beta, \\
0 \leq g^{u}<\rho \Leftrightarrow \rho \leq 1-(h+\beta+\delta)<2 \rho .
\end{gathered}
$$

(a1) ensures that the lifetime utility of the emperor is bounded. The second inequality in (a2) ensures that the lifetime utility of households is bounded while the first inequality in (a2) ensures that the balancedgrowth rate is non-negative.

\section{Political Fragmentation}

Under political fragmentation, the amount of goods produced in each region is $Y_{t}=L_{t} H_{t}=\left(2 s_{t}\right) H_{t}$, where $s_{t}$ denotes the share of land claimed by an emperor. The two emperors incur defense spending to fight over the distribution of land. The gross amount of tax revenue in each region is $\tau_{t} Y_{t}$, and the fraction of tax revenue spent on defense is denoted by $d_{t} / \tau_{t}$ (i.e. $d_{t}$ is the fraction of output spent on defense). The share of land claimed by an emperor is assumed to be $s_{t}=d_{t} /\left(d_{t}+d_{t}^{\prime}\right),{ }^{9}$ where $d_{t}^{\prime}$ is the other emperor's decision on the fraction of output spent on defense. The fraction of tax revenue consumed by the emperor is denoted by $1-d_{t} / \tau_{t}$; in other words, the net amount of tax revenue consumed by the emperor is $T_{t}=\left(\tau_{t}-d_{t}\right) Y_{t}$. As before, taking $\tau_{t}$ and $s_{t}$ as given, the households choose $c_{t}$ to maximize (1) subject to (2). Then, taking the resulting solution $c_{t}\left(\tau_{t}, d_{t}, d_{t}^{\prime}\right)$ and $d_{t}^{\prime}$ as given, the emperor chooses $\tau_{t}$ and $d_{t}$ to maximize (4) subject to (2). However, the households now have the option to move to the other country. When households moves to other country, their output of goods decreases by a fraction $m \in(0,1)$. Suppose the emperors have the flexibility in levying different tax rates on domestic

\footnotetext{
${ }^{9}$ This simple functional form is assumed for analytical tractability, and this specification on the conflict resolution technology is a special case of the more general functional forms used in the literature on conflict resolution. See, for example, Hirshleifer (1991).
} 
households and immigrants. Then, in a symmetric equilibrium, the condition that prevents labor and human-capital outflows is $\tau_{t} \leq m$ for domestic households. The emperors would lower the tax rate for immigrants to zero but still fail to attract labor and human-capital inflows.

Lemma 2: Under political fragmentation, the balanced-growth equilibrium outcomes are

$$
\begin{gathered}
c^{f}=\frac{\rho}{\left(1-\tau^{f}\right)(2 s)}, \\
\tau^{f}=\min (m, \beta+1 / 3), \\
g^{f}=1-\left(\tau^{f}+\rho+\delta\right) .
\end{gathered}
$$

For $m>\beta+1 / 3, d=1 / 3$. For $m \leq \beta+1 / 3, d=m\left(\frac{1-m+\beta}{1-m+3 \beta}\right) \leq 1 / 3$. For $m \in(0,1), s=0.5$.

Proof: See Appendix A. $\square$

Intuitively, if the mobility cost is sufficiently high, then the emperors would choose a gross tax rate that is equal to the sum of their desired net tax rate given by $\beta$ and the Nash-equilibrium amount of defense spending given by $d=1 / 3$. If the mobility cost is sufficiently low, then the emperors would be forced to set a lower tax rate and allocate a smaller amount of resources to defense spending. To ensure that the balanced-growth equilibrium is well-behaved, the following parameter conditions are assumed.

$$
\begin{gathered}
g^{f}<\beta \Leftrightarrow 1-(\rho+\delta)-\min (m, \beta+1 / 3)<\beta, \\
0 \leq g^{f}<\rho \Leftrightarrow \rho \leq 1-\delta-\min (m, \beta+1 / 3)<2 \rho,
\end{gathered}
$$

The interpretations for (a3) and (a4) are analogous to the ones for (a1) and (a2).

\section{Growth Effects of Political Fragmentation vs. Political Unification}

The condition that determines whether economic growth is higher under political fragmentation or political unification is given by 


$$
g^{f}>g^{u} \Leftrightarrow h>\tau^{f}-\beta \Leftrightarrow h>\min (m, \beta+1 / 3)-\beta
$$

In other words, political fragmentation is more favorable to growth than political unification if and only if the heterogeneity costs are sufficiently high. When the mobility cost is not a binding constraint (i.e. $m>\beta+1 / 3$ ), the relevant comparison is between the relative magnitude of the heterogeneity costs and the equilibrium amount of defense spending given by $d=1 / 3$. When the mobility cost becomes a binding constraint, the relevant comparison is between the relative magnitude of the heterogeneity costs and the mobility cost that limits the tax rate levied by an emperor. In this case, as the emperor becomes more impatient, he/she would prefer to levy a higher tax rate; as a result, the parameter space in which political fragmentation is more favorable to growth than political unification increases. These results are summarized in Proposition 1, Figure 1 and Corollary 1.

Proposition 1: For $m>\beta+1 / 3$, political fragmentation is more favorable to growth than political unification if and only if $h>d=1 / 3$. For $m \leq \beta+1 / 3$, political fragmentation is more favorable to growth than political unification if and only if $h>m-\beta$.

Proof: Note (11). $\square$

Figure 1: Results of Proposition 1

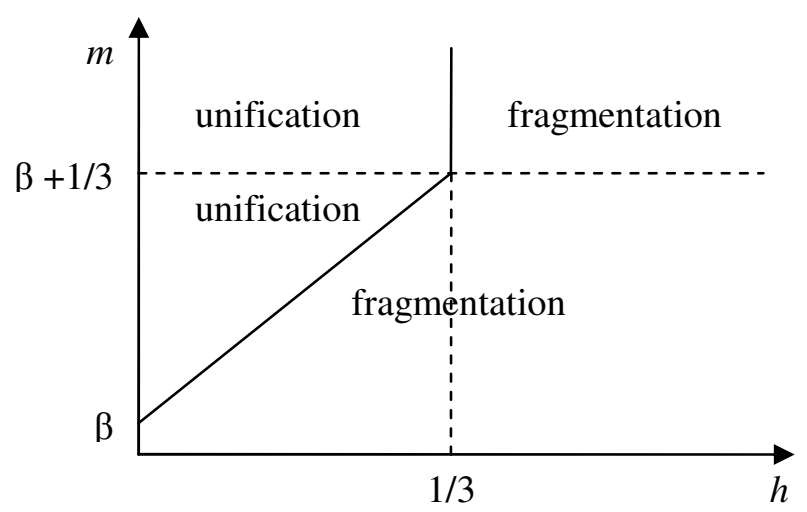


Corollary 1: For $m \leq \beta+1 / 3$, an increase in $\beta$ enlarges the parameter space in which political fragmentation is more favorable to growth than political unification.

Proof: Note (11).

\section{Endogenous Political Regime}

Suppose the political regime is chosen by the emperors. Then, which political regime do they prefer? In particular, this section considers whether the emperors would always prefer the political regime that is more favorable to growth. Because this simple version of the AK model does not exhibit transition dynamics, the lifetime utility of an emperor can be simplified to

$$
\tilde{U}=\int_{0}^{\infty} e^{-\beta t} \ln \left(T_{0} e^{g t}\right) d t=\frac{\ln T_{0}}{\beta}+\frac{g}{\beta^{2}} .
$$

In the case of political fragmentation, the initial level of tax revenue is $T_{0}^{f}=\left(\tau^{f}-d\right) H_{0}$, where $H_{0}$ is the exogenously given stock of human capital at time 0 and is normalized to 1 without loss of generality. As for the case of political unification, it requires an additional assumption on the revenue sharing between the two emperors. A natural benchmark is the following.

Assumption: In the case of political unification, the two emperors cooperate together to rule the unified country and share the tax revenue equally.

Given this setting, the initial level of tax revenue consumed by each emperor is $T_{0}^{u}=\tau^{u}(1-h) H_{0}$. Substituting $T_{0}^{u}, \tau^{u}$ and $g^{u}$ into (12) yields (13), in which $\tilde{U}^{u}$ denotes the lifetime utility of each emperor under political unification.

$$
\tilde{U}^{u}=\frac{\ln \left(\tau^{u}(1-h)\right)}{\beta}+\frac{g^{u}}{\beta^{2}}=\frac{\ln \beta}{\beta}+\frac{1-(h+\beta+\rho+\delta)}{\beta^{2}} .
$$


As for the lifetime utility of an emperor under political fragmentation, it depends on whether the mobility cost is a binding constraint. For $m>\beta+1 / 3$, substituting $T_{0}^{f}, \tau^{f}, d$ and $g^{f}$ into (12) yields

$$
\tilde{U}^{f}=\frac{\ln \left(\tau^{f}-d\right)}{\beta}+\frac{g^{f}}{\beta^{2}}=\frac{\ln \beta}{\beta}+\frac{1-(1 / 3+\beta+\rho+\delta)}{\beta^{2}}
$$

Proposition 2: For $m>\beta+1 / 3, \tilde{U}^{f}>\tilde{U}^{u}$ if and only if $g^{f}>g^{u}$.

Proof: Note (13) and (14).

In other words, when the mobility cost is not a binding constraint, the emperors would choose the political regime that is more favorable to growth. Intuitively, the two political regimes affect an emperor's utility through a level effect and a growth effect, and the level effect is reflected in the initial level of tax revenue. In the case of political unification, $T_{0}^{u}$ is potentially reduced by the heterogeneity costs, but the emperor sets $\tau^{u}=\beta /(1-h)$ to offset this effect. In the case of political fragmentation, $T_{0}^{f}$ is potentially reduced by the equilibrium amount of defense spending, but the emperor sets $\tau^{f}=\beta+d$ to offset this effect as well. Therefore, it turns out that $T_{0}^{u}=T_{0}^{f}$, so that only the growth effect is present.

When the mobility cost is a binding constraint (i.e. $m<\beta+1 / 3$ ), substituting $T_{0}^{f}, \tau^{f}, d$ and $g^{f}$ into (12) yields

$$
\tilde{U}^{f}=\frac{\ln \left(\tau^{f}-d\right)}{\beta}+\frac{g^{f}}{\beta^{2}}=\frac{\ln \beta}{\beta}-\frac{1}{\beta} \ln \left(\frac{1-m+3 \beta}{2 m}\right)+\frac{1-(m+\rho+\delta)}{\beta^{2}}
$$

The extra term given by $\beta^{-1} \ln ((1-m+3 \beta) / 2 m)>0$ for $m<\beta+1 / 3$ reflects an emperor's utility loss from being unable to choose the desired tax rate. The tax competition between the emperors results into a negative level effect through the reduction in the initial level of tax revenue. Because of the presence of this negative level effect, the emperors may have a lower utility under political fragmentation even when this political regime is more favorable to growth. Proposition 3 and Figure 2 summarize this finding. 
Proposition 3: For $m<\beta+1 / 3$, there exists a range of parameters, in which $g^{f}>g^{u}$ but $\tilde{U}^{f}<\tilde{U}^{u}$. This range of parameters is given by $h \in(m-\beta, \bar{h})$, where $\bar{h} \equiv m-\beta+\beta \ln ((1-m+3 \beta) / 2 m)$.

Proof: From Proposition 1, $g^{f}>g^{u} \Leftrightarrow h>m-\beta$. From (13) and (15), $\tilde{U}^{f}<\tilde{U}^{u} \Leftrightarrow h<\bar{h}$. When $m<\beta+1 / 3, \bar{h}>m-\beta$ for any value of $m \in(0,1)$ and $\beta \in(0,1)$. Therefore, $h \in(m-\beta, \bar{h})$ is a nonempty parameter space. $\square$

Figure 2: Results of Proposition 3

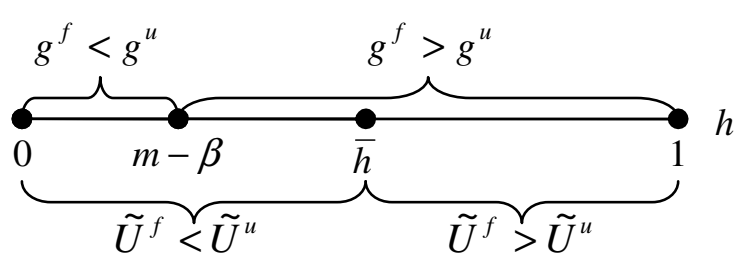

Intuitively, when the heterogeneity costs are sufficiently high such that $h>m-\beta$, the positive growth effect is larger under political fragmentation than political unification. However, because the mobility cost is a binding constraint, the emperors also suffer from the negative level effect under political fragmentation. When the heterogeneity costs are not excessively high such that $h<\bar{h}$, the negative level effect dominates the positive growth effect, and the emperors enjoy a higher utility under political unification. Figure 3 plots the equilibrium growth rate when the political regime is endogenously chosen by the emperors to maximize their utility for the case in which the mobility cost is a binding constraint.

\section{Figure 3: Equilibrium Growth under Endogenous Political Regime}

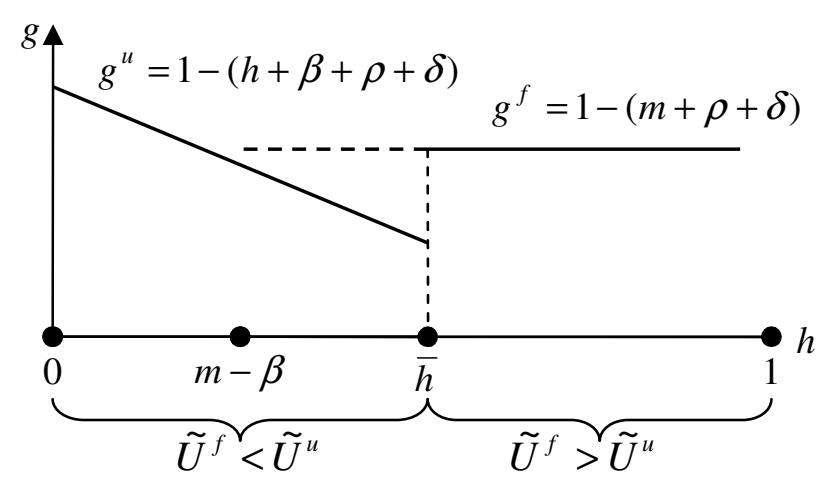




\section{Welfare of Households}

As for the households, they always prefer the political regime that is more favorable to growth. To see this result, the lifetime utility of a household is re-expressed as

$$
U=\int_{0}^{\infty} e^{-\rho t} \ln \left(C_{0} e^{g t}\right) d t=\frac{\ln C_{0}}{\rho}+\frac{g}{\rho^{2}} .
$$

Denote the household's lifetime utility under political fragmentation and under political unification by $U^{f}$ and $U^{u}$ respectively.

Proposition 4: $U^{f}>U^{u}$ if and only if $g^{f}>g^{u}$.

Proof: Firstly, note that $C_{0}=c(1-\tau)(1-\gamma h)(2 s) H_{0}$. Then, from (5) and (8), $C_{0}^{f}=C_{0}^{u}=\rho H_{0} . \square$

The initial level of consumption $C_{0}$ is potentially affected by the income-tax rate $\tau$ and the level of productivity $A_{0}=(1-\gamma h)(2 s)$. However, as shown in (5) and (8), the household always chooses $c=\rho /\left((1-\tau) A_{0}\right)$ to offset these effects and consumes a fraction $\rho$ of the human-capital stock. Because the households always prefer the growth-maximizing regime, there are situations in which the households and the emperors prefer different political regimes. Corollary 2 summarizes this finding.

Corollary 2: For $m<\beta+1 / 3$, there exists a range of parameters given by $h \in(m-\beta, \bar{h})$, in which $U^{f}>U^{u}$ but $\tilde{U}^{f}<\tilde{U}^{u}$

Proof: It follows from Proposition 3 and Proposition 4. $\square$

\section{Conclusion}

This paper develops an endogenous-growth model to analyze the conditions under which economic growth is higher under political fragmentation than political unification. In order to formalize the different 
growth effects of each political regime in a theoretical model, I have made a number of simplifying assumptions and used specific functional forms. The simple model certainly does not capture all the important elements of the nation-state and united-empire systems but nonetheless serves the useful purpose in providing a simple framework that highlights the different growth effects of the heterogeneity costs under political unification and the interstate competition in taxation and defense spending under political fragmentation.

I believe that the following insights are more general than my specific model. Under political unification, the heterogeneity costs have a negative effect on the economy. Under political fragmentation, the interstate competition in defense spending has a negative effect on the economy while the mobility of citizens causes tax competition between rulers and has a positive effect. Although the abstract model may have neglected other important characteristics of each political regime, ${ }^{10}$ whether political fragmentation or political unification is more favorable to growth should be at least partly determined by the relative magnitude of the above three factors. Furthermore, when the political regime is chosen by the rulers, they do not necessarily choose the growth-maximizing regime. This finding potentially explains why so many ancient civilizations, except for Europe, adopted the united-empire system while the nation-state system might have been more favorable to economic growth. Perhaps the heterogeneity costs in Europe were higher than, for example, in ancient China such that the European rulers found political fragmentation optimal while the Chinese rulers found political unification optimal despite the possibility that political fragmentation would have been more favorable to growth and preferred by the citizens.

\footnotetext{
${ }^{10}$ For example, Jones (1981) argues that the nation-state system provided Europe with an insurance mechanism through policy diversification and political variety.
} 


\section{References}

1. Acemoglu, Daron (2008) "Introduction to Modern Economic Growth" book manuscript.

2. Alesina, Alberto; and Spolaore, Enrico (2003) "The Size of Nations" The MIT Press, Cambridge, MA.

3. Alesina, Alberto; and Spolaore, Enrico (2005) "War, Peace, and the Size of Countries" Journal of Public Economics, vol. 89, p. 1333-1354.

4. Bernholz, Peter; Streit, Manfred E.; and Vaubel, Roland (1998) "Political Competition, Innovation and Growth: A Historical Analysis" Springer-Verlag, Berlin, Germany.

5. Bernholz, Peter; and Vaubel, Roland (2004) "Political Competition, Innovation and Growth in the History of Asian Civilizations" Edward Elgar, Cheltenham, UK.

6. Brennan, Geoffrey; and Buchanan, James M. (1977) "Towards a Tax Constitution for Leviathan" Journal of Public Economics, vol. 8, p. 255-273.

7. Drazen, Allan (2000) "Political Economy in Macroeconomics" Princeton University Press, Princeton, New Jersey.

8. Grossman, Herschel I. (2002) “Make Us a King': Anarchy, Predation and the State” European Journal of Political Economy, vol. 18, p. 31-46.

9. Grossman, Herschel I.; and Noh, Suk Jae (1994) "Proprietary Public Finance and Economic Welfare" Journal of Public Economics, vol. 53, p. 187-204.

10. Hirshleifer, Jack (1991) "The Technology of Conflict as an Economic Activity” American Economic Review, vol. 81, p. 130-134.

11. Jones, Eric L. (1981) “The European Miracle” Cambridge University Press, Cambridge, UK.

12. North, Douglass (1981) "Structure and Change in Economic History" Norton, New York.

13. Persson, Torsten; and Tabellini, Guido (2000) "Political Economics: Explaining Economic Policy" The MIT Press, Cambridge, MA.

14. Rebelo, Sergio (1991) “Long-Run Policy Analysis and Long-Run Growth" Journal of Political Economy, vol. 99, p. 500-521. 


\section{Appendix A}

Lemma 1: Under political unification, the balanced-growth equilibrium outcomes are

$$
\begin{gathered}
c^{u}=\frac{\rho}{\left(1-\tau^{u}\right)(1-h)}, \\
\tau^{u}=\beta /(1-h), \\
g^{u}=\left(1-\tau^{u}\right)(1-h)-(\rho+\delta)=1-(h+\beta+\rho+\delta) .
\end{gathered}
$$

Proof: The current-value Hamiltonian for the representative household is

$$
\mathrm{H}_{t}=\ln \left(c_{t}\left(1-\tau_{t}\right)(1-h) H_{t}\right)+\mu_{t}\left(\left(1-c_{t}\right)\left(1-\tau_{t}\right)(1-h)-\delta\right) H_{t} .
$$

The first-order conditions are

$$
\begin{gathered}
\frac{\partial \mathrm{H}_{t}}{\partial c_{t}}=\frac{1}{c_{t}}-\mu_{t}\left(1-\tau_{t}\right)(1-h) H_{t}=0, \\
\frac{\partial \mathrm{H}_{t}}{\partial H_{t}}=\frac{1}{H_{t}}+\mu_{t}\left(\left(1-c_{t}\right)\left(1-\tau_{t}\right)(1-h)-\delta\right)=\mu_{t} \rho-\dot{\mu}_{t}, \\
\frac{\partial \mathrm{H}_{t}}{\partial \mu_{t}}=\left(\left(1-c_{t}\right)\left(1-\tau_{t}\right)(1-h)-\delta\right) H_{t}=\dot{H}_{t} .
\end{gathered}
$$

Solving (A5) - (A7) yields $c=\rho /((1-\tau)(1-h))$ and $g \equiv \dot{H}_{t} / H_{t}=(1-\tau)(1-h)-(\rho+\delta)$. The current-value Hamiltonian for the emperor is

$$
\widetilde{\mathrm{H}}_{t}=\ln \left(\tau_{t}(1-h) H_{t}\right)+\tilde{\mu}_{t}\left(\left(1-\tau_{t}\right)(1-h)-(\rho+\delta)\right) H_{t} .
$$

The first-order conditions are

$$
\frac{\partial \tilde{\mathrm{H}}_{t}}{\partial \tau_{t}}=\frac{1}{\tau_{t}}-\tilde{\mu}_{t}(1-h) H_{t}=0
$$

$$
\frac{\partial \tilde{\mathrm{H}}_{t}}{\partial H_{t}}=\frac{1}{H_{t}}+\tilde{\mu}_{t}\left(\left(1-\tau_{t}\right)(1-h)-(\rho+\delta)\right)=\tilde{\mu}_{t} \beta-\dot{\tilde{\mu}}_{t}
$$




$$
\frac{\partial \tilde{\mathrm{H}}_{t}}{\partial \tilde{\mu}_{t}}=\left(\left(1-\tau_{t}\right)(1-h)-(\rho+\delta)\right) H_{t}=\dot{H}_{t} .
$$

Solving (A9) - (A11) yields $\tau=\beta /(1-h)$ and $g=1-(h+\beta+\rho+\delta)$. $\square$

Lemma 2: Under political fragmentation, the balanced-growth equilibrium outcomes are

$$
\begin{gathered}
c^{f}=\frac{\rho}{\left(1-\tau^{f}\right)(2 s)}, \\
\tau^{f}=\min (m, \beta+1 / 3), \\
g^{f}=1-\left(\tau^{f}+\rho+\delta\right) .
\end{gathered}
$$

For $m>\beta+1 / 3, d=1 / 3$. For $m \leq \beta+1 / 3, d=m\left(\frac{1-m+\beta}{1-m+3 \beta}\right) \leq 1 / 3$. For $m \in(0,1), s=0.5$.

Proof: The current-value Hamiltonian for the representative household is

$$
\mathrm{H}_{t}=\ln \left(c_{t}\left(1-\tau_{t}\right)\left(2 s_{t}\right) H_{t}\right)+\mu_{t}\left(\left(1-c_{t}\right)\left(1-\tau_{t}\right)\left(2 s_{t}\right)-\delta\right) H_{t}
$$

The first-order conditions are

$$
\begin{gathered}
\frac{\partial \mathrm{H}_{t}}{\partial c_{t}}=\frac{1}{c_{t}}-\mu_{t}\left(1-\tau_{t}\right)\left(2 s_{t}\right) H_{t}=0, \\
\frac{\partial \mathrm{H}_{t}}{\partial H_{t}}=\frac{1}{H_{t}}+\mu_{t}\left(\left(1-c_{t}\right)\left(1-\tau_{t}\right)\left(2 s_{t}\right)-\delta\right)=\mu_{t} \rho-\dot{\mu}_{t}, \\
\frac{\partial \mathrm{H}_{t}}{\partial \mu_{t}}=\left(\left(1-c_{t}\right)\left(1-\tau_{t}\right)\left(2 s_{t}\right)-\delta\right) H_{t}=\dot{H}_{t} .
\end{gathered}
$$

Solving (A16) $-(\mathrm{A} 18)$ yields $c=\rho /((1-\tau)(2 s))$ and $g=(1-\tau)(2 s)-(\rho+\delta)$. The current-value Hamiltonian for the emperor is

$$
\tilde{\mathrm{H}}_{t}=\ln \left(\left(\tau_{t}-d_{t}\right)\left(\frac{2 d_{t}}{d_{t}+d_{t}^{\prime}}\right) H_{t}\right)+\tilde{\mu}_{t}\left(\left(1-\tau_{t}\right)\left(\frac{2 d_{t}}{d_{t}+d_{t}^{\prime}}\right)-(\rho+\delta)\right) H_{t}
$$


The first-order conditions are

$$
\frac{\partial \tilde{\mathrm{H}}_{t}}{\partial d_{t}}=\frac{-1}{\tau_{t}-d_{t}}+\frac{1}{d_{t}}-\frac{1}{d_{t}+d_{t}^{\prime}}+\tilde{\mu}_{t}\left(1-\tau_{t}\right)\left(\frac{2 d_{t}^{\prime}}{\left(d_{t}+d_{t}^{\prime}\right)^{2}}\right) H_{t}=0
$$

$$
\frac{\partial \tilde{\mathrm{H}}_{t}}{\partial H_{t}}=\frac{1}{H_{t}}+\tilde{\mu}_{t}\left(\left(1-\tau_{t}\right)\left(\frac{2 d_{t}}{d_{t}+d_{t}^{\prime}}\right)-(\rho+\delta)\right)=\tilde{\mu}_{t} \beta-\dot{\tilde{\mu}}_{t},
$$

$$
\frac{\partial \tilde{\mathrm{H}}_{t}}{\partial \tilde{\mu}_{t}}=\left(\left(1-\tau_{t}\right)\left(\frac{2 d_{t}}{d_{t}+d_{t}^{\prime}}\right)-(\rho+\delta)\right) H_{t}=\dot{H}_{t}
$$

Imposing symmetry and solving (A20) - (A23) yield $\tau=\beta+d, d=1 / 3$, and $g=1-(\tau+\rho+\delta$ ).

Now suppose $m \leq \beta+1 / 3$. Then, $\tau=m$, and (A20) drops out of the optimization problem. (A21) (A23) become

$$
\begin{gathered}
\frac{\partial \tilde{\mathrm{H}}_{t}}{\partial d_{t}}=\frac{-1}{m-d_{t}}+\frac{1}{d_{t}}-\frac{1}{d_{t}+d_{t}^{\prime}}+\tilde{\mu}_{t}(1-m)\left(\frac{2 d_{t}^{\prime}}{\left(d_{t}+d_{t}^{\prime}\right)^{2}}\right) H_{t}=0 \\
\frac{\partial \tilde{\mathrm{H}}_{t}}{\partial H_{t}}=\frac{1}{H_{t}}+\tilde{\mu}_{t}\left((1-m)\left(\frac{2 d_{t}}{d_{t}+d_{t}^{\prime}}\right)-(\rho+\delta)\right)=\tilde{\mu}_{t} \beta-\dot{\tilde{\mu}}_{t} \\
\frac{\partial \tilde{\mathrm{H}}_{t}}{\partial \tilde{\mu}_{t}}=\left((1-m)\left(\frac{2 d_{t}}{d_{t}+d_{t}^{\prime}}\right)-(\rho+\delta)\right) H_{t}=\dot{H}_{t} .
\end{gathered}
$$

Imposing symmetry and solving (A24) $-(\mathrm{A} 26)$ yield $d=m(1-m+\beta) /(1-m+3 \beta)$. 